\title{
Effect of Heating Method on Hydrogen Production by Biomass Gasification in Supercritical Water
}

\author{
Qiuhui Yan, ${ }^{1}$ Hong Zhang, ${ }^{1}$ Bingjie Sun, ${ }^{1}$ and Liejin Guo ${ }^{2}$ \\ ${ }^{1}$ School of Environmental and Municipal Engineering, Xian University of Architecture and Technology, Xian 710049, China \\ ${ }^{2}$ State Key Laboratory of Multiphase Flow in Power Engineering, Xian Jiaotong University, Xian 710049, China \\ Correspondence should be addressed to Liejin Guo; lj-guo@mail.xjtu.edu.cn
}

Received 13 March 2014; Accepted 27 May 2014; Published 17 June 2014

Academic Editor: Yongqi Liang

Copyright (c) 2014 Qiuhui Yan et al. This is an open access article distributed under the Creative Commons Attribution License, which permits unrestricted use, distribution, and reproduction in any medium, provided the original work is properly cited.

\begin{abstract}
The glucose as a test sample of biomass is gasified in supercritical water with different heating methods driven by renewable solar energy. The performance comparisons of hydrogen production of glucose gasification are investigated. The relations between temperature raising speed of reactant fluid, variation of volume fraction, combustion enthalpy, and chemical exergy of $\mathrm{H}_{2}$ of the product gases with reactant solution concentration are presented, respectively. The results show that the energy quality of product gases with preheating process is higher than that with no preheating unit for hydrogen production. Hydrogen production quantity and gasification rate of glucose decrease obviously with the increase of concentration of material in no preheating system.
\end{abstract}

\section{Introduction}

With the rapid increase of world energy consumption and serious environmental pollutions caused by the utilization of fossil fuels, sustainable energy systems based on hydrogen as energy carrier coupled with renewable energy resources, such as solar and biomass, are considered as an effective way to resolve issues including greenhouse gas emissions, national energy security, air pollution, and energy efficiency [1]. Solar energy is the world's most abundant and promising energy resource. Compared with conventional energy, solar energy is widely distributed, high security, and so forth.

In addition, solar energy will not be controlled or monopolized by any privileged few. These advantages make the solar energy much better than conventional fossil energy. It is a worldwide issue to make good use of it [2].

The critical point of water is at $647.3 \mathrm{~K}$ and $22.1 \mathrm{MPa}$. The theory of supercritical water gasification is based on a series of unique properties of water near the critical or supercritical thermodynamic state. Because the dielectric constant and the number of hydrogen bonds are lower, and hydrogen bonds' strength is weaker than those of ambient water, supercritical water (SCW) behaves like many organic solvents so that organic compounds and gases have complete miscibility with SCW. Therefore, SCW can provide homogeneous environment for chemical reaction, which reduces the mass transfer limitations of reaction [3].

We used glucose as a model biomass in this paper because the glucose's composition is single and its aqueous solution is homogeneous; it is easier to achieve high-pressure transport of the material of high concentration. In the process of biomass gasification in supercritical water, the material was mixed with water and transported into the reactor. This paper analyzed the performance of glucose gasification in supercritical water by two different heating methods.

\section{Gasification Systems and Heating Methods}

Figure 1 shows the process of hydrogen production system without preheating process (Method 1). When the system is running, close the valve of feeding tank and open the valve on the left side of the water tank. To complete a cycle, the water at normal temperature and pressure go through the valve in water tank, and then they are delivered to the high temperature molten salt to boost the temperature and 


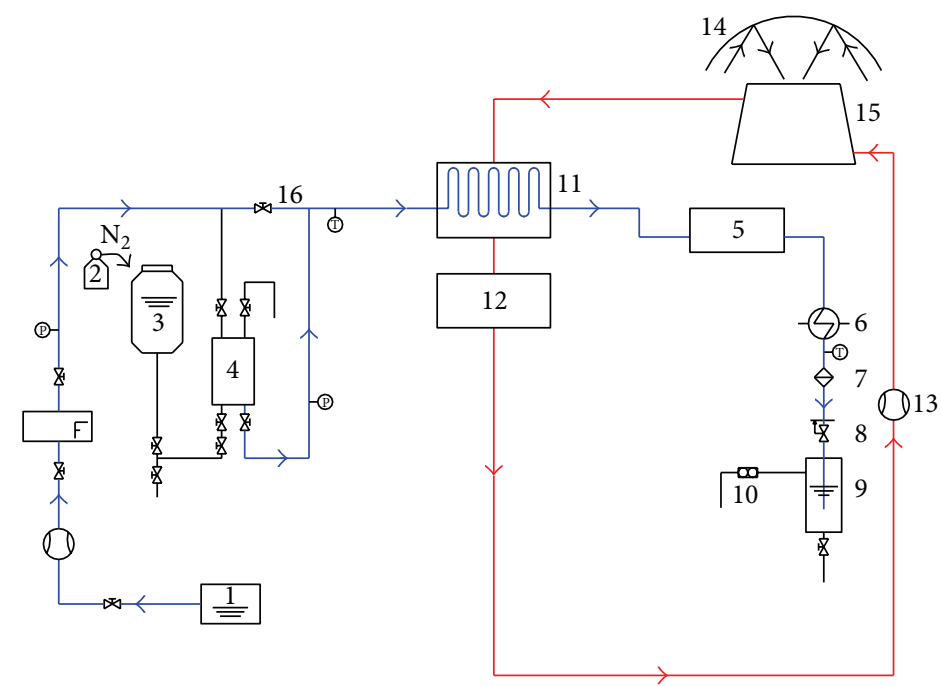

FIGURE 1: Hydrogen production without preheating process (Method 1). (1) water tank, (2) nitrogen tank, (3) storage tank, (4) feeder, (5) regenerator, (6) cooler, (7) filter, (8) back pressure regulator, (9) gas-liquid separator, (10) wet gas flow meter, (11) high temperature molten salt heat tank, (12) low temperature molten salt heat tank, (13) pump for liquid salts, (14) optical block, (15) solar receiver, and (16) valve.

pressure by the high-pressure plunger, after which they go through the regenerator, the cooler, the back pressure valve, and the gas-liquid separator sequentially. After a period of time of operation, reheat each device in the system, then close the valve on the left side of the water tank, open the feeding tank valve, and press the biomass reaction materials (cold fluid, room temperature) into the solar receiver by the piston type charging tank to realize heating gasification reaction.

Figure 2 shows the process of hydrogen production system with preheating process (Method 2).

Among the two figures, the blue line, red line, pink line, and green line represent the molten salt, the preheated water, and the mixture, respectively. The main difference between the two methods is that the fluid in reactor is directly heated by high temperature molten salt heat tank in Method 1, while the fluid in reactor is heated by high temperature molten salt heat tank and hot water from the regenerator in Method 2 simultaneously. In Method 2, water is pumped into the reactor directly and pressurized in the reactor, and the reactor is heated to bring up the system to the setting temperature and pressure. When the temperature and pressure reach the desired values, the feeder is connected to the reactor and preheated pipe is opened simultaneously (no preheated pipe in Method 1). At the exit of the reactor, product flow is rapidly cooled by a cooler. A regulator of back pressure is used to reduce the exit pressure. After leaving the back pressure regulator, the products after reaction pass through a glass gasliquid separator and are collected and analyzed.

Analysis of the gas product is accomplished by the use of a Hewlett-Packard model 6890 gas chromatograph with thermal conductivity detectors. The carrier is helium, and carrier gas flow rate is $10 \mathrm{~mL} / \mathrm{min}$. A Carbon-2000 capillary column is used, operating at $60^{\circ} \mathrm{C}$ for 2 mins, followed by a $30^{\circ} \mathrm{C} / \mathrm{min}$ ramp to $150^{\circ} \mathrm{C}$, hold for 2 mins, then a $20^{\circ} \mathrm{C} / \mathrm{min}$ ramp to $190^{\circ} \mathrm{C}$, and a $5 \mathrm{~min}$ hold at $190^{\circ} \mathrm{C}$.

\section{Results}

3.1. The Heating Mode of Reactor. It is an endothermic reaction that converts biomass into hydrogen in supercritical water. The reactor should be supplied heat to maintain the normal reaction. According to the heating position, it can be divided into internal heating and external heating. The external heating is usually provided by electric, nuclear, thermal, or other heat sources. The internal heating can be provided by electric, parallel chemical reaction or other methods. The external heating is relatively easy to be implemented. But the temperature of the reactor wall is higher than the temperature of the fluid in the reactor, so as to get the same fluid temperature; it is more strict on the heat-resistant of the reactor, especially in the case of large temperature difference of heat transfer. In addition, for small experimental device, even if the reactor wall is continuously heated, the temperature of the fluid in reactor decreases and is hard to rise because the experiment is endothermic, which makes it difficult to meet the requirements of heat in the reaction. Experiments show that, when the flow of high temperature water is larger, the temperature of fluid at reactor entrance changed a little after the reactants are pressed into the reactor. Otherwise, the temperature of fluid at reactor entrance decreases. These experimental results can be deduced obviously in this paper (Figures 3 4). Figures 3 and 4 show the variation of the temperature of fluid at reactor entrance with time on the condition that the glucose is pressed into the reactor when the preheated high temperature water is $1.0 \mathrm{~kg} / \mathrm{h}$ and $2.5 \mathrm{~kg} / \mathrm{h}$ and the flow rate of glucose is $0.5 \mathrm{~kg} / \mathrm{h}$ [4]. It is shown that, when the heating rate is higher, more $\mathrm{H}_{2}$ and less macromolecular hydrocarbon are generated [5]. That is to say, the effect of gasification is better. The internal heating provided by electric is between them. 


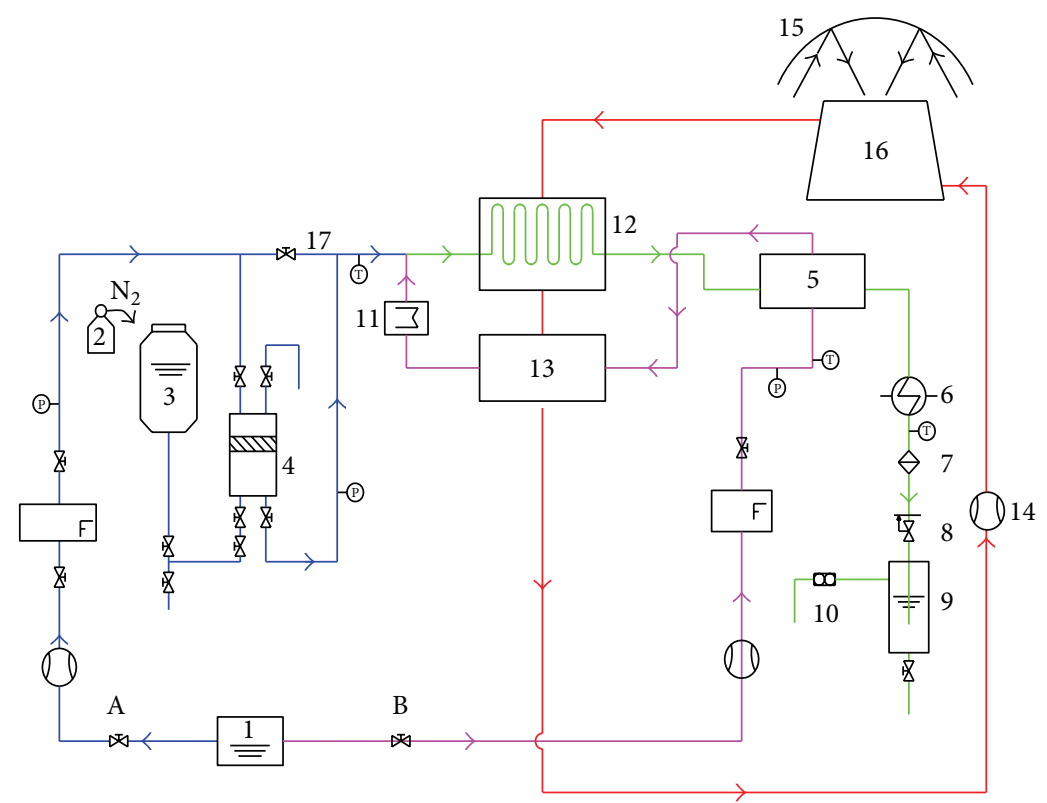

FiguRE 2: Hydrogen production system with preheating process (Method 2). (1) water tank, (2) nitrogen tank, (3) storage tank, (4) feeder, (5) regenerator, (6) cooler, (7) filter, (8) back pressure regulator, (9) gas-liquid separator, (10) wet gas flow meter, (11) electric heater, (12) high temperature molten salt heat tank, (13) low temperature molten salt heat tank, (14) pump for liquid salts, (15) optical block, (16) solar receiver, and (17) valve.

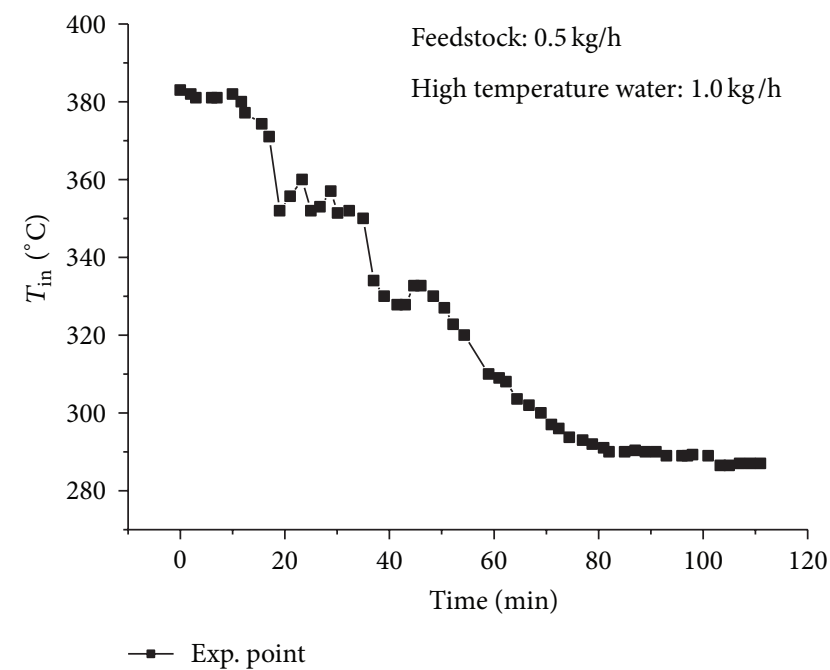

FIGURE 3: The variation of fluid temperature at the reactor inlet with time (small flow high temperature water).

3.2. Comparison of Gasification Product Components. For biomass in supercritical water, hydrolysis, pyrolysis, steam reforming, water transformation, and methanation reaction process can occur, generating a large number of intermediates which will introduce other chemical reactions and thus make the overall reaction mechanism more complicated. Biomass gasification in SCW could be summarized into three major reactions:

$$
\mathrm{CH}_{x} \mathrm{O}_{y}+(1-y) \mathrm{H}_{2} \mathrm{O}=\mathrm{CO}+\left(\frac{x}{2}+1-y\right) \mathrm{H}_{2}
$$

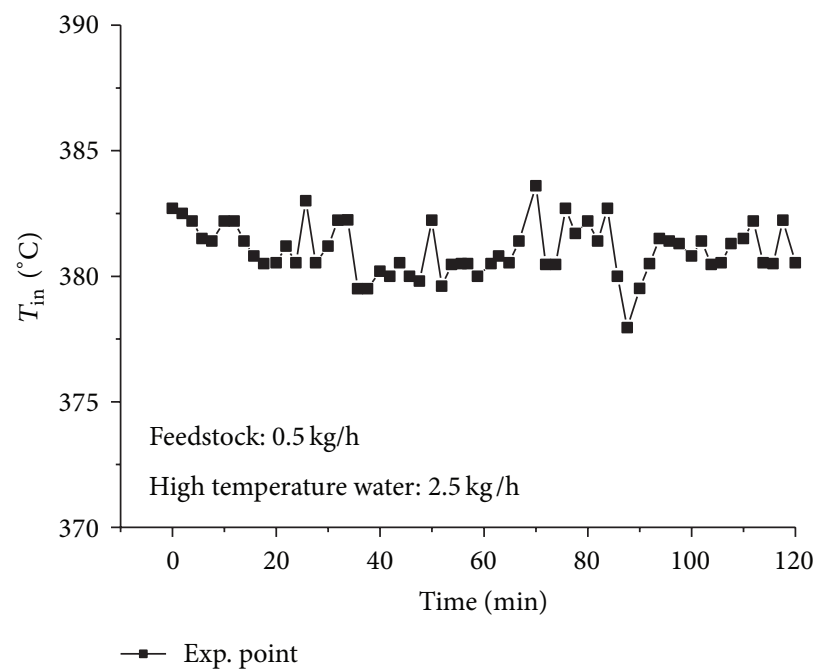

FIGURE 4: The variation of fluid temperature at the reactor inlet with time (large flow high temperature water).

$$
\begin{aligned}
& \mathrm{CO}+\mathrm{H}_{2} \mathrm{O}=\mathrm{CO}_{2}+\mathrm{H}_{2} \\
& \mathrm{CO}+3 \mathrm{H}_{2}=\mathrm{CH}_{4}+\mathrm{H}_{2} \mathrm{O}
\end{aligned}
$$

Tables 1 and 2 show the product gas volume fraction of different concentration of glucose solution gasification in SCW by Method 1 and Method 2 [6]. With the increase of the concentration, the volume fraction of $\mathrm{H}_{2}$ in Method 1 decreased from $33.90 \%$ to $18.94 \%$, almost by half, and it decreased rapidly from $28.50 \%$ to 19.62 while the concentration changed from $3.3 \%$ to $5 \%$. It decreased because 
TABLE 1: The product gas volume fraction of different mass concentration of glucose solution gasification in SCW by Method $1\left(600^{\circ} \mathrm{C}\right.$; $25 \mathrm{MPa})$.

\begin{tabular}{lcccccc}
\hline \multirow{2}{*}{ Glucose concentration } & \multicolumn{5}{c}{ Product gas volume fraction/\% } \\
\cline { 2 - 3 } & $\mathrm{H}_{2}$ & $\mathrm{CO}$ & $\mathrm{CH}_{4}$ & $\mathrm{CO}_{2}$ & $\mathrm{C}_{2} \mathrm{H}_{4}$ & $\mathrm{C}_{2} \mathrm{H}_{6}$ \\
\hline $1.7 \%$ & 33.90 & 24.30 & 2.50 & 37.90 & 0.50 & 0.50 \\
$3.3 \%$ & 28.50 & 30.60 & 5.60 & 34.30 & 0.50 & 0.50 \\
$5 \%$ & 19.62 & 14.23 & 30.47 & 35.69 & 0.50 & 0.60 \\
$10 \%$ & 18.94 & 6.02 & 18.24 & 56.82 & 0.70 \\
\hline
\end{tabular}

TABLE 2: The product gas volume fraction of different mass concentration of glucose solution gasification in SCW by Method $2\left(600^{\circ} \mathrm{C}\right.$; $25 \mathrm{MPa}$ ).

\begin{tabular}{lcccccc}
\hline \multirow{2}{*}{ Glucose concentration } & \multicolumn{5}{c}{ Product gas volume fraction/\% } \\
& $\mathrm{H}_{2}$ & $\mathrm{CO}$ & $\mathrm{CH}_{4}$ & $\mathrm{CO}_{2}$ & $\mathrm{C}_{2} \mathrm{H}_{4}$ & $\mathrm{C}_{2} \mathrm{H}_{6}$ \\
\hline $1.7 \%$ & 35.97 & 26.44 & 2.20 & 34.19 & 0.60 & 0.60 \\
$3.3 \%$ & 35.66 & 25.63 & 2.24 & 35.25 & 0.61 & 0.61 \\
$5 \%$ & 35.67 & 26.28 & 2.00 & 34.88 & 0.60 & 0.57 \\
$10 \%$ & 34.21 & 26.84 & 2.11 & 35.53 & 0.53 \\
\hline
\end{tabular}

the concentration of the material increase will make the amount of water involved in the reaction (1) become less, which is not conducive for reaction (1) and thus decrease the yield of hydrogen. The volume fraction of $\mathrm{H}_{2}$ changed a little in Method 2 just from $35.97 \%$ to $34.21 \%$, and the volume fraction of $\mathrm{H}_{2}$ has been almost equal when the concentration increased from $1.7 \%$ to $3.5 \%$; volume fraction of $\mathrm{CO}_{2}$ increased from $37.9 \%$ to $56.82 \%$ produced by nonpreheating process, which increased about 1.5 times, and the volume fraction of $\mathrm{CO}$ and $\mathrm{CH}_{4}$ increased first and then decreased. The volume fraction of product by preheating process is increased, and the other 4 kinds of gas components are stable. The volume fraction of $\mathrm{H}_{2}$ by Method 2 is higher than that by Method 1 at all conditions of glucose concentration. This is because Method 2 has the preheating process, which makes the material heating rate become faster. Given that the hydrogen production quantity was in direct proportion to the heating rate [7], the production in Method 2 is higher than that in Method 1.

3.3. Comparison of the Combustion Enthalpy and Chemical Exergy of $\mathrm{H}_{2}$. Combustion enthalpy and chemical exergy of hydrogen represent the degree of biomass energy conversion to hydrogen energy, namely, utilization to the degree of conversion. It can be seen from Figures 5 and 6 that the hydrogen combustion enthalpy and chemical exergy have obvious differences by different heating way. The hydrogen combustion enthalpy and chemical exergy vary rapidly with the increasing of the concentration. Combustion enthalpy changes in the proportion of span from $47.79 \%$ to $14.59 \%$, and the proportion of chemical exergy changes span from $43.89 \%$ to $13.03 \%$ by Method 1, while the hydrogen combustion enthalpy and chemical exergy fraction produced by Method 2 are very stable, basically reaching $48 \%$ and $44 \%$, and material concentration has little effects on hydrogen combustion enthalpy and chemical exergy. Therefore, the energy quality of product gases by Method 2 is higher than

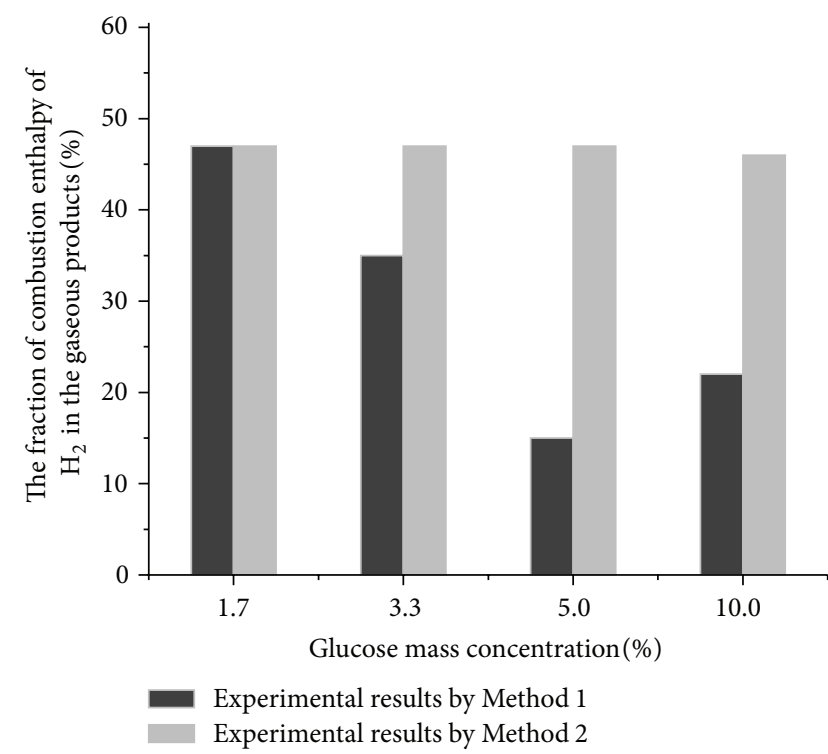

FIGURE 5: The variation of combustion enthalpy fraction of $\mathrm{H}_{2}$ with the glucose concentration in the gaseous products.

that by Method 1 for objective gas $\mathrm{H}_{2}$, and the gasification and energy utilization are high and stable.

\section{Conclusion}

When the preheated high temperature water flow rate is large, the fluid temperature at the reactor inlet changes a little after the reactant is pressed into the reactor. Otherwise, the inlet temperature decreases rapidly. Hydrogen production and energy quality of product gases with preheating process are higher than that with no preheating unit for hydrogen production. The hydrogen combustion enthalpy and chemical exergy vary rapidly with the increase of the reactant 


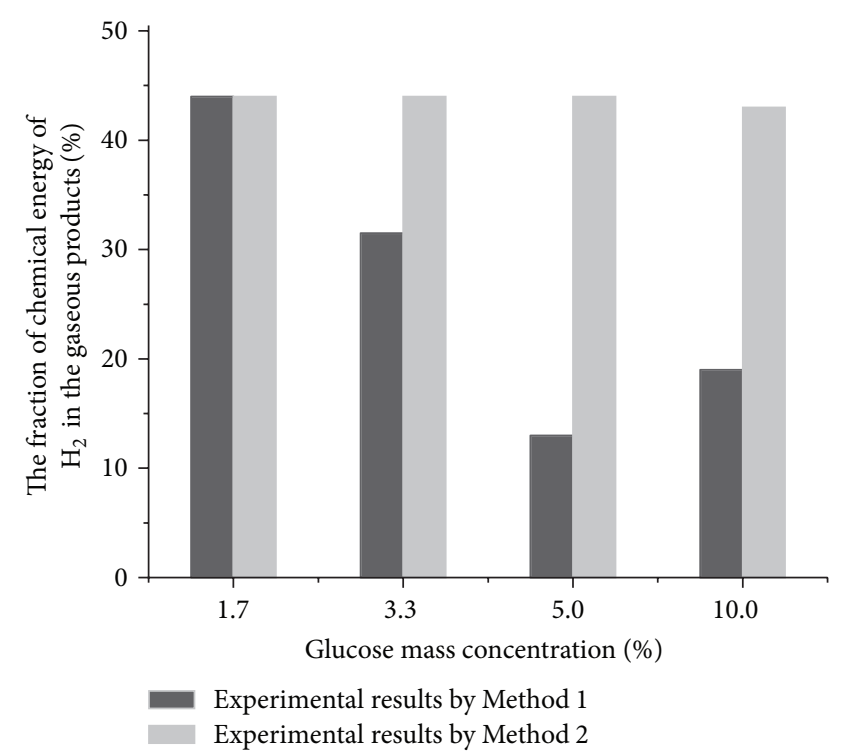

FIGURE 6: The variation of chemical exergy fraction of $\mathrm{H}_{2}$ with the glucose concentration in the gaseous products.

concentration by Method 1, while the hydrogen combustion enthalpy and chemical exergy vary a little and the reactant concentration has little effects on them by Method 1 .

\section{Conflict of Interests}

The authors declare that there is no conflict of interests regarding the publication of this paper.

\section{Acknowledgments}

This work was financially supported by the National Natural Science Foundation of China (Contract no. 51323011) and the open fund of State Key Laboratory of Multiphase Flow in Power Engineering and Department of Education Project of Shaanxi Province through Contract no. 12JK0788.

\section{References}

[1] R. F. Susanti, J. Kim, and K.-P. Yoo, "Supercritical water gasification for hydrogen production: current status and prospective of high-temperature operation," in Supercritical Fluid Technology for Energy and Environmental Applications, pp. 111-137, 2014.

[2] Y. Lu, L. Guo, X. Zhang, and C. Ji, "Hydrogen production by supercritical water gasification of biomass: Explore the way to maximum hydrogen yield and high carbon gasification efficiency," International Journal of Hydrogen Energy, vol. 37, no. 4, pp. 3177-3185, 2012.

[3] J. Sánchez-Oneto, J. R. Portela, and E. J. Martínez de la Ossa, "Supercritical water oxidation for wastewater destruction with energy recovery," in Supercritical Fluid Technology for Energy and Environmental Applications, pp. 181-190, 2014.

[4] Q. Yan, Hydrogen Production from Co-Gasification of Biomass and Coal in Supercritical Water, Xi'an Jiaotong University, Xi'an, Shaanxi China, 2007.
[5] G. T. Hong and M. H. Spitzer, "Supercritical water partial oxidation," in Proceedings of the U.S.DOE Hydrogen Program Review, NREL/CP-610-32405, pp. 1-18, 2002.

[6] B. Wang, Optimization of Hydrogen Production from Biomass Gasification in Supercritical Water by Concentrated Solar, Xian University of Architecture and Technology, Xian, China, 2012.

[7] G. T. Hong and M. H. Spitzer, "Supercritical water partial oxidation," in Proceedings of the U.S.DOE Hydrogen Program Review, NREL/CP-610-32405, pp. 1-18, 2002. 

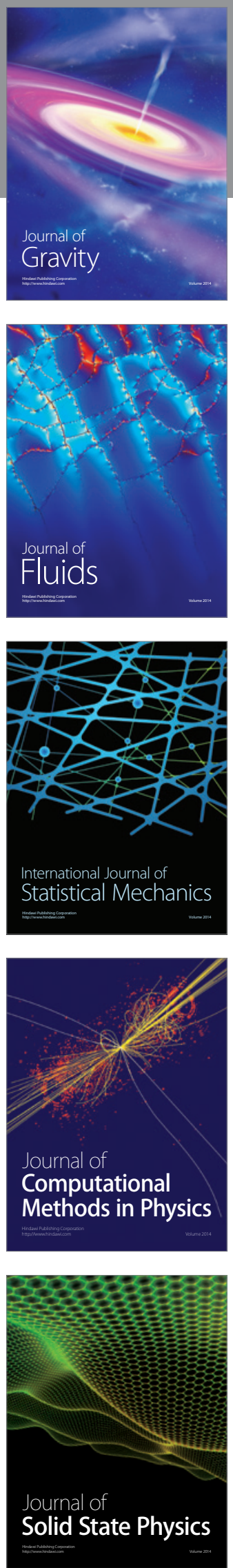

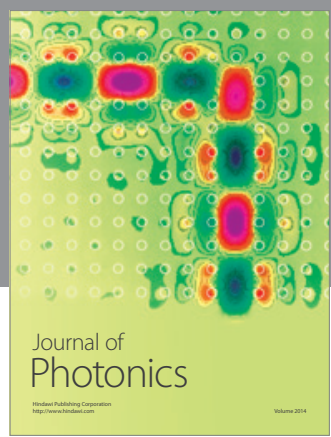

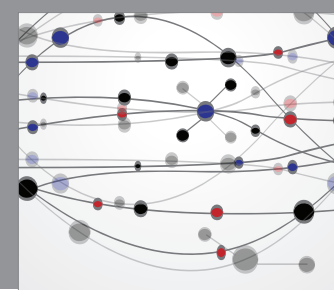

The Scientific World Journal

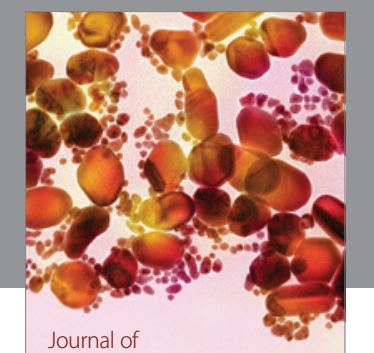

Soft Matter
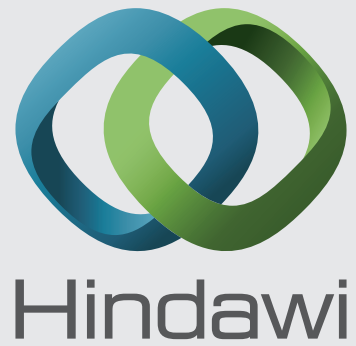

Submit your manuscripts at

http://www.hindawi.com
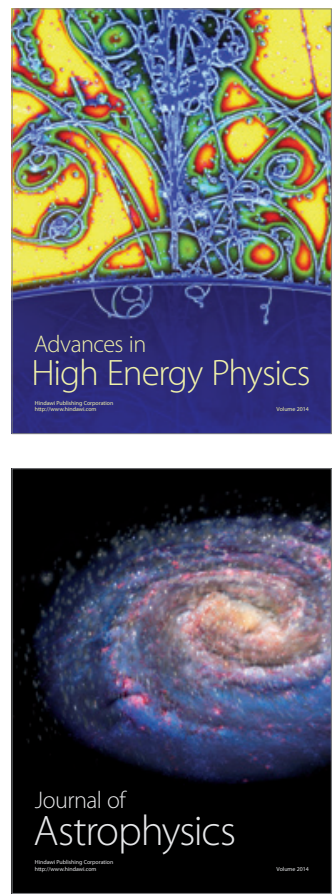
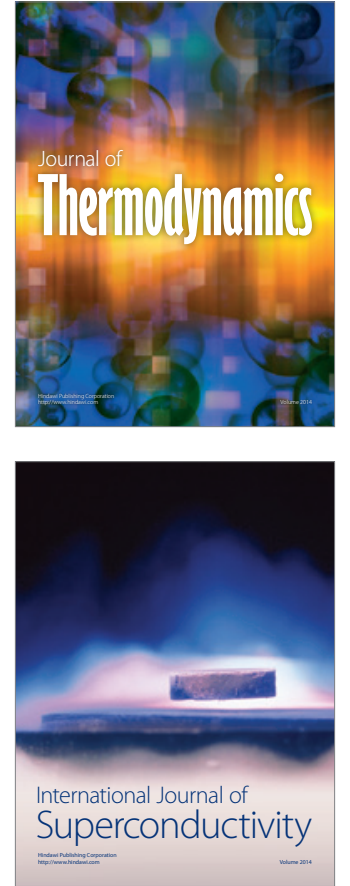
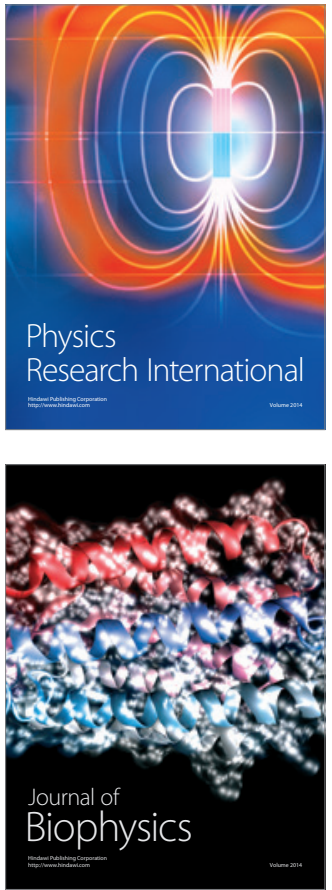
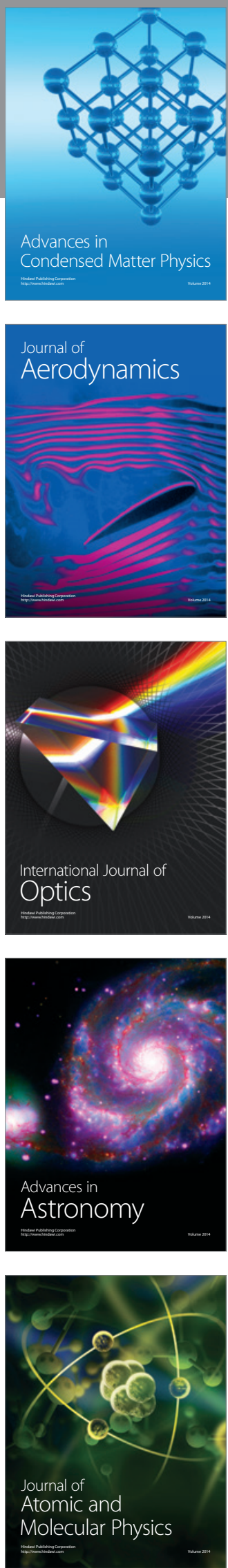